This item was submitted to Loughborough's Research Repository by the author.

Items in Figshare are protected by copyright, with all rights reserved, unless otherwise indicated.

\title{
The medium on the stage: trance and performance in nineteenth-century spiritualism
}

PLEASE CITE THE PUBLISHED VERSION

http://dx.doi.org/10.1080/17460654.2011.601166

\section{PUBLISHER}

(C) Taylor \& Francis

\section{VERSION}

AM (Accepted Manuscript)

\section{PUBLISHER STATEMENT}

This work is made available according to the conditions of the Creative Commons Attribution-NonCommercialNoDerivatives 4.0 International (CC BY-NC-ND 4.0) licence. Full details of this licence are available at: https://creativecommons.org/licenses/by-nc-nd/4.0/

\section{LICENCE}

CC BY-NC-ND 4.0

\section{REPOSITORY RECORD}

Natale, Simone. 2019. "The Medium on the Stage: Trance and Performance in Nineteenth-century Spiritualism”. figshare. https://hdl.handle.net/2134/19417. 
Simone Natale

University of Torino, Italy

536 Rue Rose-de-Lima, H4C 2L4 Montreal - Quebec, Canada

Email: simone.natale@gmail.com

The medium on the stage: Trance and performance in nineteenth-century spiritualism

\author{
Simone Natale \\ University of Torino (Italy)
}

\begin{abstract}
Whilst historians of spiritualism have been eager to focus on its political and social implications, less attention has been given to the fact that spirit communication was also a matter of visual spectacle. This article aims to analyze spiritualist séances as a form of spectacular entertainment. Relying on a wide array of spiritualist sources, it argues that séances were not only meant as moments of religious and scientific inquiry, but also as a brilliant amusement where theatrical effects embellished an exciting shared experience. The intermingling of religion and entertainment can thus be seen as one of the defining characteristics of the spiritualist experience. After sketching the history of the presence of spiritualist mediums on the stage and discussing the involvement of professionalism in mediumship, the article will then focus on the trance as a specific performance strategy. It will examine how the trance combined issues of automatism, theatricality and absorption, and contributed to the coexistence in spirit séances of spectacular features and claims of authenticity.
\end{abstract}

Keywords: spiritualism; trance; automatism; performance; stage magic. 
One afternoon in the 1880s, the spiritualist John Wetherbee and his two friends were uncertain about what to do, and looked over the list of local mediums performing that day: “'Well,' said they, after the civilities were over, 'what is there going on this afternoon? Where can we go and see something?' - meaning spiritual manifestations. We looked over the list; there were five or six interesting chances, but we could take in but one" (Wetherbee 1885, 231). Finally, they decided to go and see the Berry sisters, who were materializing mediums. The abundance of choice of "what to see" was one of the things that made Wetherbee proud of his home city, Boston. Where else could one find such a concentration of mediums? As he put it, "look at the meetings for spiritualist teachings that this locality sustains. See the number of mediums that dispense the idea [...]; and with regard to the more sensuous phenomena there seems to be in this city about all the time a dozen mediums for materialization, to say nothing about other physical phenomena" (Wetherbee 1885, 282).

To the contemporary reader, the narrative of this amusement-seeking spiritualist in nineteenth-century Boston, recalls the act of choosing a movie in local theatre. Indeed, although spirit séances have been usually analysed as social constructs in which matters of politics, science, and religion were put into question, authors such as Alex Owen have also recognized the presence of a theatrical frame that regulated the communication with the spirits (Owen 1990). In this article, I will approach the dark spaces of spiritualist séances from this perspective, which leads to the identification of séances as entertaining and spectacular devices. As Daniel Herman noted, in fact, it was through the mechanism of séances that spiritualism "offered entertainment by encouraging believers and non-believers to test its truth" (Herman 2006, 432). Relying on a wide array of spiritualist sources, I will argue that séances were not only meant as moments of religious and scientific inquiry, but also as a brilliant amusement where theatrical effects embellished an exciting shared experience. The climax of these events culminated in the occurrence of the spirit contact, 
often presented in dramatic ways, as a kind of coup de théâtre around which the entire event was shaped.

The entertaining character of spirit séances was soon understood in the realm of entertainment. Traditionally, mediums had hired managers, toured countries, and advertised in the press. Also for these reasons, nineteenth-century mediums can be regarded as a class of professional performers, who, through the phenomenon of trance, shaped a complex dramatic space where theatrical performance mingled with claims of passivity and authenticity. Although the repeated exposures of fraudulent mediums provides evidence of widespread deception, there is no reason to regard all mediums as tricksters, or all sitters as curiosityseekers rather than believers. As the testimony of spiritualists such as the above-mentioned John Wetherbee suggests, séances were also regarded as spectacular and entertaining, especially by those who believed in spiritualism. The intermingling of performance and claims of authenticity, of spectacle and religious experience, is not a contradiction in spiritual séances: on the contrary, it represented the very core of the spiritualist experience.

The underlining assumption of this article is that the fact that séances could be framed for their audiences as real, does not mean that they were devoid of theatrical protocols. In this respect, it is useful to recall the argument used by Peter Lamont (2006), who relied on Goffman's notion of frame to address the difference of reception to a magician's trick and to a psychic phenomenon which is reputed by the viewers to be authentic. According to Erving Goffman, a frame is the way an individual experiences a situation, perceiving an event in terms of frameworks that give meaning to their experience. In the case of stage magic, a spectator would probably perceive the situation as a fictional spectacle that relies on trickery and sleight-of-hand; on the contrary, a spiritualist sitter at a séance would perceive it as a non-orchestrated event that implies the opening of a channel of communication with the beyond. This difference of interpretation, as Lamont suggested, contributes to establish the 
boundary between an entertaining magic trick and an allegedly genuine séance.

While the first two part of this article will give account of the forms of theatricality that were involved in the mediums' performances, the third will focus on how mediums cued audiences to regard séances as distinct from overtly theatrical performances. The question, in other words, is to understand how mediums succeeded in orchestrating a spectacle that, despite having an underlining theatrical character, could be at the same time perceived as authentic by their sitters. As I will argue, this was primarily achieved through the apex of the mediums' performance, the state of trance, that strengthened spiritualism's claims of authenticity by recalling the principles of automatism, creative absorption, and reverie.

\section{Spiritualism in the theatre: from the Fox sisters to the Davenport brothers}

The founding myth of spiritualism, the story of the Fox sisters who "discovered" spirit communication (Capron 1855), mirrors spiritualism's movement from the private towards the public sphere. Although the "Rochester rapping" of 1848, first heard in the haunted house of the Fox family in Hydesville, inaugurated the craze for spirit séance, the phenomena soon moved to more inclusive spaces. From November 14, 1849, the Fox sisters demonstrated their mediumship in Rochester's Corinthian Hall for three nights, charging seventy-five cents for admission. On the first evening, four hundred people filled the hall to hear the mysterious noises. Some months later, in June 1850, New Yorkers who were interested in attending a demonstration of the spirit rappings, could see the Fox sisters at Barnum's Hotel, where the phenomena were presented three times a day, for an admission fee of one dollar (Braude 1989, 15-16). The engagement with show-business entrepreneur P.T. Barnum, which included a popular song especially written to market it (During 2002, 153), is testimony to the commercial approach of this first tour of the Fox sisters' table rapping. 
spiritualist mediums felt equally at ease in theatres and halls as they did in domestic spaces. Performing before large audiences was considered part of the medium's moral duties. Thus, Catherine Berry wrote that "I have never regretted having devoted my services to the cause in so public a manner. On the contrary, I feel some degree of pride in having passed through such a trying ordeal pro bono publico" $(1876,136)$. In many cases, the spectators attending such performances were subject, as in theatre shows or public lectures, to the payment of an admission fee. Séance-sitting was thus often a matter of theatregoing: mediums performed in halls and theatres as frequently as within the confines of the Victorian house. In doing so, they gave birth to a tradition of spectacular spirit manifestations, and standardised mediumship as an activity to be held before a public.

A particularly successful type of spiritualist performance was trance-lecturing. Replicating the figure of the lecturer, a well-established profession in the cultural field, mediums in the United States and later in Europe offered themselves as the channel through which the spirits delivered discourses before large audiences. According to Ann Braude, trance-lecturing was one of the first ways in which women had the opportunity to speak in public in nineteenth-century America. Quite often, their "spirits controls" delivered discourses that touched on pressing social and political issues, including the institution of marriage and the condition of women in Victorian society (Braude 1989).

Mediumship was also legally associated with public speaking. In August 1872, the popular British medium J. J. Morse entered the list of professional speakers of England. In his autobiography, Leaves from My Life, Morse gave an account of the reception of his first trance-lecture on April 21, 1870, when his control delivered a "regular address" through him: "the event was a complete success, and my advent as a trance-speaker was welcomed with pleasure by all" $(1877,23)$. During his subsequent career as a public medium, he performed before "large and influential audiences in all the large towns in three out of the four divisions 
of the United Kingdom” (24). His lecturing control, Tien-Sien-Tie (fig. 1), presented himself as the spirit of a Chinese mandarin of the second class, and delivered discourses on religious, philosophical, and spiritual issues.

Public events organized by spiritualists included a wide range of performances and features. Instrumental music was offered in exhibitions of spiritualist phenomena that included trance-lecturing, as advertisements on spiritualist magazines and publications state (Anon. 1882). Spiritualist groups often found it convenient to establish a space where it was possible to host a large number of people: the circles gathering around the British magazine The Medium and Daybreak, for instance, often advertised public evenings and exhibitions (fig. 2), and in March 1885 solemnly inaugurated a new "Hall for Spiritualists" (fig. 3) in Blackburn with a lecture, the projection of spirit drawings and spirit photographs, and selections of vocal and instrumental music (Anon. 1885). In the United States, spiritualists even organized summer camp meetings (Moore 1997). J. J. Morse, reporting his impressions after a journey to the United States, described these camps as merging spirit séances and entertainment. At 10:30 pm "lights out" brought "the labours and pleasures of the day to a close". Among the events that most contributed to the amusement of the campers, Morse listed the "phantom party", an evening party where all participants were masked as ghosts, and the "Old Folks' Concert", a concert held in the open air, "in which all the performers were attired in the costumes of a century ago, and all the airs and words were dated back to the same period" (Morse 1877, 51-52).

Although most mediums relied primarily on patronage to finance themselves, "public" mediums could be supported at least in part by the paying public of their séances. Some of them specialized in a kind of spiritualist shows that bore evident relations to contemporary stage magic. Several historians of conjuring have documented how nineteenthcentury entertainment magic actively exploited the fascination for the occult (During 2002; 
North 2008; Beckman 2003). As the Russian physicist Dmitrij Ivanovič Mendeleev pointed out in the second of the three lectures he wrote on spiritualism, the difference between magicians and mediums was that the former explicitly admitted they were performing trickery (Mendeleev 1992, 39). Magicians such as Robert Houdin and John Nevil Maskelyne made it clear that in their shows the supernatural played no role, and that everything was accomplished through the means of sleight of hand as well as optical and mechanical tricks. Nevertheless, the boundaries between mediumship and magic was quite hard to distinguish, and some spiritualists went so far as to suggest that famous stage magicians might have psychic and spiritual gifts. ${ }^{1}$ John Wetherbee, for instance, described magicians as mediums with fairly good mediumistic powers, who had decided that it was more profitable to use them in their performances: "It is a matter of dollars and cents with them. I could name a man who is a good medium for physical manifestations, but likes the popularity and the reputation that he gets from the skeptical world better than poverty with truth" (Wetherbee $1885,208)$. The difference between mediums and magicians was also a matter of performance style: as Peter Lamont noted, magicians tended to operate their tricks with apparent ease, while mediums appeared exhausted after the séances, suggesting that their contact with the spirit world required an intense physical effort (Lamont 2006, 27).

Among those mediums who performed spiritualist shows similar to stage magic, the Davenport brothers became particularly prominent. As they toured the United States and Great Britain in the 1860s and 1870s, they conducted séances on the stage in theatres and public halls, as well as in smaller rooms before a selected audience. The fact that their feats were considered of supernatural origins was central for the success of their shows. George Smith-Buck, writing under the pseudonym of Herr Dobler, thoroughly described their shows in a book that was intended to unmask their tricks. The setting of their séances was designed to form an adequate environment for a spectacular event. For instance, since séances were 
usually supposed to take place in darkness, a "spirit cabinet" placed on the stage allowed the Davenports to perform before a large audience without imposing upon the spectators the necessity of sitting a long time in the dark (Dobler 1869).

Ira Erastus and William Henry Davenport were born in Buffalo, in the state of New York, in 1839, and 1841 respectively. Their mediumship was revealed early during their childhood: according to their biographer T. L. Nichols, the Davenport family was "disturbed" by spirit raps in 1846, two years before the Hydesville rappings became public (Nichols 1864, 12). After their mediumship had become well-known in Buffalo, Ira and William left and toured the United States, accompanied initially by their fathers, and then by people who acted as their agents and assistants. Among those were figures involved in the world of show business, such as Harry Kellar, who later became one of the leading American magicians. At least one of their managers, a Mr. Palmer, also managed stage conjurors (Lamont 2006, 23).

At the beginning of their séances, the Davenport brothers were usually tied with ropes by a member of the audience, to make sure that they played no role in the developing of spirit phenomena. The participation of the audience, called on the stage to find out if the protocols were correct, suggests that the success of their spiritualist shows also relied, like stage magic, on the public's engagement: spectators attending the Davenports' shows were encouraged to actively question the reality of spirit manifestations and the claims of spiritualism. As cultural historian James W. Cook convincingly demonstrated, much of nineteenth-century spectacular features, including those promoted by show-business entrepreneur P. T. Barnum, exploited the means by which the public was stimulated to form a personal opinion about the authenticity of the attractions. Barnum increased the public's curiosity via his sophisticated use of the press, supplying newspapers with evidence either for or against the authenticity of his attractions, to stimulate rumour and debate (Cook 2001). Similarly, contemporary exposés of the Davenport brothers by magicians such as Maskelyne and Cook in London might have 
ultimately helped the Davenports' box-office success (Dobler 1869; Maskelyne 1876). After all, testing the truth of spirit communication was the principal activity of sitters in all spiritual séances.

Music played a very relevant role in the Davenports' shows. Their most famous and cited manifestation was the playing of musical instruments by spirits. During a private séance they held in London, when they performed before a selected audience of twenty-four attendants, ${ }^{2}$ the housekeeper sent someone to a neighbouring music seller for six guitars and two tambourines, to ensure that the instruments to be used would not be those the mediums were familiar with. After the Davenports had been tied in the cabinet, the instruments started to play magically, and members of the public claimed to have been grasped by spirit hands (Doyle 1926, 1: 99-100). The Davenports' spirit concerts could include guitars and tambourines, as well as violins, horns, and bells (Cooper 1867, 130).

The attitude of spiritualists toward the mediumship of the Davenport brothers was ambivalent. As Arthur Conan Doyle reported in his history of the movement, by making a profession of their gifts, the Davenports had worked at a lower level than more traditional mediums, "and yet by their crude methods they got their results across to the multitude in a way which a more refined mediumship could not have done" (Doyle 1926, 1: 96). Many spiritualists defended their work, responding to magicians who had tried to unmask the Davenports' trickery. Thus, an oration delivered in London in 1873 attempted a counterexposure of magicians' anti-spiritualist shows, highlighting the fact that "we have in London at this moment several conjurers who night after night attempt by mere trickery to show phenomena something like those that take place in the presence of spirit-mediums, and to burlesque and ridicule the whole subject of spirit communion" (Sexton 1873, 6). Others, however, worried that such spectacularization of spiritualism could have negative effects on the movement. J. J. Morse, for instance, openly criticized the more commercial approach of 
American mediums, who charged an admission fee and regularly advertised in the popular press, noting that "it is somewhat disagreeable to see the function of mediumship reduced to the level of show business" (Morse 1877, 54).

\section{Professional mediums}

As the medium Emma Hardinge recognized, roots of mediumship can be found in the mesmeric performers, who practised the art also known as animal magnetism, a technique created by the Austrian physician and occultist Franz Anton Mesmer at the end of the eighteenth century. Mesmerists relied on theories about vital fluids governing the universe, whose manipulation by the healer could exercise a beneficial power on the patient, as well as on an ante litteram use of hypnosis, which became customary in medicine and psychology only in the second half of the nineteenth century (Darnton 1968). "In nearly every [American] city, town, or hamlet," Hardinge wrote in 1870, "the itinerant mesmerizer made his rounds, operating upon chance subjects as opportunity offered, and alternately exciting superstitious terror or wrathful antagonism by the exciting of his seemingly magical powers" (Britten 1870, 22). As Terry M. Parssinen documented, the entertaining character of the activity of these performers was often underlined by detractors as well as by advocates of mesmerism. These performers were probably entrepreneurs that made a living out of mesmerism, drawing on the traditions of popular entertainment, scientific lecturing, and lay healing (Parssinen 1977).

In a similar manner to mesmeric performances, the institution of mediumship was also challenged by the apparent contradiction between the spiritualist belief and the commercial and professional approach of many practitioners. Spiritualists often acknowledged that performances of mediums could include some acting, at least to give some more "colour" to the manifestations. John Wetherbee, who had become a convinced 
spiritualist after the death of his first-born son, admitted that "I have seen, of course, attempts to cheat by at least supplementing their powers by more or less imposition; not always meaning to do anything wrong, but, perhaps, to give more for the fee received than the spirits can do through them" $(1885,207)$. The analogy between stage performers and mediums was reinforced by the fact that some mediums had entered into spiritualism's influence directly from the show-business. The career of trance lecturer Emma Hardinge, for instance, had started in theatres rather than in spiritual séances: initially, she had tried unsuccessfully to launch a career as an actress (Oppenheim 1985, 7; Owen 1990, 54-55). Moreover, mediumship was understood not only as a natural gift, but as a skill that could be improved by regular training. As biographic accounts testify, becoming a medium was a gradual process that required, as with acting, abnegation and experience. George A. Redman wrote in his autobiography (1859) that, after he had started developing mediumistic powers, he could perceive "wonderful progress" as each day rolled on. Manifestations often improved in complexity and variety during a medium's career. As a spiritualist put it, "the gift of mediumship requires developing by constant sitting, in the same way that a musical or an artistic talent requires to be cultivated; and a person can therefore no more become at once a 'full-blown' medium than he could expect to be a proficient instrumentalist without previous practice" (Fritz 1873, 42).

The link between mediumship and performance was often related to accusations of trickery and fraud, and was therefore highly controversial within the spiritualist field. Given the number of documented exposures of fraudulent mediums, it was easy for opponents of spiritualism to argue that mediums were actors who consciously played a role. For this reason, polemics and debates surrounding the professionalism of mediums, who often charged a fee from those attending their séances or relied on patronage, were frequent in the spiritualist field. Nevertheless, most of the leading figures of spiritualism kept defending the 
professional nature of mediumship. In 1878, for instance, a spiritualist claimed that giving a payment to a medium for performing his duty "is as praiseworthy as to employ the time and 'gifts' of a lawyer, doctor, baker, or any other tradesman who has goods for sale, mental or material", and that refusing to pay was "equivalent to pocket-picking": also in the spiritualist field, after all, 'the question of work and fees comes under the heading of 'supply' and 'demand,' and will be regulated accordingly" (Coates 1878). In common with this perspective, successful mediums in the nineteenth century advertised in the press, toured in their countries and abroad, and even hung signs to promote their business.

In the nineteenth century, mediumship was a very competitive business. Every medium had their own speciality, often claiming its superiority in comparison with other manifestations. Redman, for instance, who was a direct-writing and materialization medium, lamented that in almost every spiritualist community, mediums and believers were to be found, who expressed disgust for those "tangible manifestations of spirit presence" and proclaimed the trance speaker and the clairvoyant as superior orders of development. His defence of rapping and direct writing came together with an argument against the reliability of trance speaking:

\footnotetext{
"Every idea expressed through such channels, is tainted, more or less, with the characteristics of the brain through which it comes; and without doubt we may take seven-tenths of such matter at a discount. The only perfect mode of spirit communion free from mortal interference is, where the communication given is wholly mechanical, and disconnected entirely from the mind of the medium, which can be obtained in various ways, - by rapping, tipping, or writing in such a manner, that the medium cannot read it at the time" (Redman 1859, 107, emphasis in original).
}

Since the advent of spiritualism, mediums discovered they had to tailor their 
manifestations to the demands of the public. This opened the way to an increasing spectacularization and sensationalism in spirit phenomena. As R. Laurence Moore noted, spirit concerts such as those delivered through the mediumship of the Davenport brothers had a relevant advantage: they could be performed before a crowd $(1977,16)$. Various, increasingly original apparitions competed for attention within the spiritualist field, replacing in part the "old" phenomena of direct writing and trance speaking. Thus, the FrenchAmerican medium Lucie Marie Curtis Blair, whose career began in 1872, toured the United States demonstrating her ability to paint flowers while blindfolded (Braude 1989, 175). Others specialized in dance mediumship, or in the apparition of flowers (Berry 1876, 97). In common with stage magic and show business, innovation and novelty played a relevant role in establishing the success of a professional medium. Innovations were as customary as the imitations of successful phenomena. The American magician Harry Houdini, who thoroughly studied the history of spiritualism and published a book on this topic in 1924, noted that "even a casual examination of Spiritualistic history and development shows that just as soon as a medium forms a new alliance with the psychic power dispenser and produces phenomena unknown before, other mediums immediately begin to produce it also and the new manifestation becomes epidemic". This had been the case, for instance, of spirit photography: "no one had thought of such a possibility before Mumler [the first spirit photographer] invented the mystery, but talented mediums everywhere when they heard of his pictures began to produce them also" (Houdini 1924, 119-120).

Spiritualism was not immune to dynamics of pre-cinematic stardom, too. The most popular mediums, such as the Fox sisters, the Scottish Daniel Douglas Home and, later, the Neapolitan Eusapia Palladino, were acclaimed by spiritualist circles in Europe and the United States, and performed their séances with prominent personalities and members of aristocracy sitting at their table. The career of such great mediums was often controversial, including 
moments of zenith as well as disastrous decadence. The Fox sisters, for instance, remained among the prominent spiritualist celebrities for their entire lives, but passed from the glorious status of founders of the movement to something similar to the rank of falling stars: through repeated admissions of trickery in the phenomena of rapping (Davenport 1888), troubled sentimental lives, and a pathological attachment to alcohol, they attracted again and again the attention of the spiritualist world.

The story of Daniel Douglas Home is an exemplar of the elevation of "star" mediums. In the late 1850s, Home succeeded in startling the spiritualist field with his spectacular manifestations exhibiting a new degree of evolution and complexity. In his history of French spiritisme, John Warne Monroe has given an interesting account of the triumphant reception of Home's 1857 tour in France. Despite being doubtful about the authenticity of his phenomena, a journalist of Le Siècle so described Home's spectacular manifestations, that overcame any other spiritualist phenomena previously experienced in France: "tables tilt without being touched, and the objects on them remain immobile, contradicting all the laws of physics. The walls tremble, the furniture stamps its feet, candelabra float, unknown voices cry from nowhere - all the phantasmagoria of the invisible populate the real world" (Monroe 2008, 86). Home's charismatic character certainly had a role in stimulating the interest of the public for this elegant and fashionable British man. His "astonishing career" convinced Arthur Conan Doyle to depict him as "the greatest [medium] in a physical sense that the world has ever seen" $(1926,1: 87)$. His most successful and wellknown feat was levitation: it was said that he had been able to float in the air in good light, before reputable witnesses such as several Lords in Great Britain and high French noblemen, more than a hundred times (1: 90). In 1877, at the end of his career, he published a book, Lights and Shadows of Spiritualism, a best seller within spiritualist literature, that ridiculed the performances of other mediums as bad trickery, and exalted the authenticity and wonder 
of the manifestations he had been able to produce (1877).

\section{The spectacle of trance}

Through an analysis of the forms of theatricality that were involved in spiritualist séances, the first two sections of this article have examined how séance sitting can be regarded as a form of spectatorship, and mediumship as a performance. In this last section, I will now question how the medium's performance stimulated sitters to frame séances as a communication with the otherworld, rather than as a spectacular event. To answer this question, it is necessary the discussion of the phenomenon of trance, that was recognized by spiritualists as the most relevant manifestation of mediumship. Although the state of trance has been rarely regarded as a matter of performance in the dramatic sense, ${ }^{3}$ understanding mediumship as an activity that might have a theatrical character opens the way for its interpretation as a staged behaviour that gave rise to highly spectacular effects.

When mediums fell into a trance, the actions they performed were considered to be disconnected from their own will. As a medium put it, the only perfect mode of spirit communion was "wholly mechanical, and disconnected entirely from the mind of the medium” (Redman 1859, 107). This argument, supporting spiritualism's scientific claims, was connected to the understanding of machines as objective means. As authors such as Lorraine Daston and Peter Galison (2007) demonstrated, automatism was acquiring an increasingly relevant status within the conceptualization of scientific evidence in the nineteenth century, when spiritualism first developed into a mass movement. This faith in the evidentiary power of recording machines was recalled in the discourse stressing the scientific value of messages and phenomena delivered automatically through the medium.

One of the key arguments deployed by spiritualists to demonstrate the authenticity of spiritualist phenomena was the naivety of spirit mediums. Since mediums had to be mere 
channels through which spirit agency manifested themselves, their ignorance, ingenuity, and inexperience were often underlined as a further evidence that the hypothesis of trickery and fraud had to be refused. It is probably for this reason that spiritualists frequently recognized powerful mediumistic powers in the children. The story of the Fox sisters, a kind of founding myth for the spiritualist movement, relies on a similar understanding of childhood as a locus of manifestation for mediumship: the two young girls were made ultimately responsible for the "discovery" of spirit communication. Childhood played such a role in this narrative, that the younger Kate Fox was depicted as a more powerful medium than her sister: as Emma Hardinge pointed out, "the manifestation became more powerful in the presence of Kate, the youngest sister, than with any one else" (Britten 1870, 38).

If most spiritualist accounts focused on the question of automatism and "mechanical" trustworthiness, trance mediumship was also frequently connected to the act of artistic creation and to intellectual life. Under the condition of trance, mediums delivered lectures, wrote messages, stimulated physical manifestations, even drew and painted. Descriptions of mediumistic phenomena mentioned their involuntary as well as their aesthetic character, since these two aspects were intrinsically linked. Thus Charles Hammond of Rochester, New York, reporting on the mediumistic phenomenon of trance-dancing, wrote that "the movements are very eccentric, yet often exceedingly graceful", noting at the same time that "no one who danced desired it, neither could they stop it" (Britten 1870, 110). Other automatic trance-performances, such as the playing of piano by people who were not trained to do it, resulted in the astonishment of the attendants for both the wonder of trance automatism and the aesthetic value of the musical performance.

An early commentary on spiritualism expressed this tension between spontaneous action and art. Considering the adequacy of automatic mental action, the author Charles Beecher explained: 


\footnotetext{
"Instrumental representative of mind, the brain is capable of spontaneous action, without mind. Such spontaneous action will be indistinguishable from mental operations proper.

Musicians perform automatically. Printers set type mechanically. In revery, all manner of things are done unconsciously" $(1853,12)$.
}

By bringing together type printing, revery, and the performance of a musician, Beecher evoked the principles of mechanical automatism on one side, and creative absorption on the other side. In a similar way, the author of an 1869 historical survey into spiritualism and clairvoyance, J. M. Peebles, compared mediumship with artistic inspiration, since mediums were influenced by the spiritual atmosphere, "by pouring down upon us love-waves of heavenly inspiration, levelling up humanity at large, the same as the sun attracts and unfolds the floral beauties of all landscapes" (Peebles 1869, 208).

Mediumistic trance was also linked with dreaming and visions. A medium described the process of falling into trance as though a black curtain was placed before her eyes: "for a moment by looking down she can see the floor beneath her, then the curtain comes down with a rush, and all is blank" (Oyston 1885, 307). In an article on The Spiritual Magazine, the boundaries between spirit communication and dreaming seem to blur: "spiritual beings belong to inner life, and when they appear to us, and have power strongly to influence us, - to make us en rapport with them, - we are powerfully drawn towards that inner state of consciousness which we call sleep and dreaming, - and which is an abstraction from the waking consciousness" (Anon. 1862, 33). Following this perspective, clairvoyance and trance were "forms of sleep less common than our nightly experience, and far more wonderful to us" (35). 
This overlapping of trance mediumship with artistic creation and dreaming may contribute to explain the way trance helps to frame the séance situation as a real event. In his book Absorption and Theatricality: Painting and Beholder in the Age of Diderot, art historian Michael Fried distinguished two dominant approaches to painting. The first one, absorption, refers to paintings where the main figure is absorbed in their intent and does not directly regard the viewer. The second one, theatricality, refers to artworks where the subjects are clearly represented in order to shape and direct the viewer's gaze. Fried gave several example of absorption, pointing to paintings that represented artists, philosophers, writers under the inspiration of the moment. The use of absorption responds to the aim of presenting the representations as though they were not explicitly intended to be regarded by an audience. The viewer is therefore drawn into the representation, made oblivious of the act of looking and thus of the fictional status involved in her position. On the contrary, theatricality tends to acknowledge the position of the spectators and the fictional interpretation of the situation (Fried 1980). ${ }^{4}$ One of the apparently most contradictory characteristics of nineteenth-century séances was that they evoked at the same time conditions of theatricality and absorption. On one hand, the complex dramaturgy and rituals shaped the viewers' situation in a way that might reinforce the understanding of their role as spectators. On the other hand, however, the state of trance, recalled in virtually every spiritual manifestation delivered through the mediums, was connected to an aesthetics of creative absorption, that contributed to fix the spontaneous character of their performance.

In conclusion, trance mediumship can be interpreted, even when it did not involve conscious acting, as a highly regulated modality of performance that spiritualist mediums employed before large crowds of sitters and spectators in the nineteenth century. By employing an aesthetics of absorption, mediums made the sitters oblivious of their position of viewers and spectators. This made possible the establishment of a situation that, despite 
being essentially theatrical, denied the fictional character of the mediums' performance. Although the denying of an overtly fictional situation was customary in drama, in the séance space this question involved much more than a suspension of disbelief. The involvement of the sitter in the ritual and, ultimately, the meaning of the séance spectacle itself relied on this claim of authenticity

To employ Goffman's notion of frame again, spiritualist séances were a spectacular device that played with the sitters' interpretation of the event. In particular, it was through the state of trance that mediums erected a frame that discouraged the sitters from recognizing themselves as spectators. Recognizing the complex spectacularization of trance phenomena helps to explain how séances and trance mediumship created theatrical environments. Trance mediumship avoided an explicit and overt acknowledgement of the shift from the world of religion to that of entertainment. This contributed to define the environment of spiritualist séances, where believers, curious and sceptics gathered to attend a spectacle of "spontaneous" manifestations.

\section{Notes}

1. Harry Houdini famously declared that his friend Arthur Conan Doyle, a devoted spiritualist, thought the magician was a powerful medium: "Sir Arthur thinks I have great mediumistic powers and that some of my feats are done with the aid of spirits. Everything I do is accomplished by material means, humanly possible, no matters how baffling it is to the layman" (Houdini 1924, 165).

2. In ordinary séances it was usually suggested to be not more than twelve, including the medium.

3. There are, however, some interesting exceptions (King 1997; Bennett 2005; Taylor 1996).

4. The categories of absorption and theatricality have been employed as an interpretative frame in different fields, including film studies (Rushton 2007, 2004; Wright 2005). 


\section{Notes on contributor}

Simone Natale is Visiting Researcher at the Mobile Media Lab, Concordia University, Montreal (Canada). His PhD dissertation, defended at the University of Torino in 2011, examines the relations between spiritualism, show business, and visual culture.

\section{References}

Anon. 1862. Sleep. The Spiritual Magazine 3 (1): 30-35.

. 1882. Thirty-fourth anniversary of modern Spiritualism: Celebration, testimonial of Mr. Hudson, and exhibition of spirit photographs. The Medium and Daybreak 13 (630): 257-263.

- 1885. The facts \& phenomena of Spiritualism: A lecture by J. Burns to be given at the opening of the New Hall, Blackburn. The Medium and Daybreak 16 (779): 160.

Beckman, Karen Redrobe. 2003. Vanishing women: Magic, film, and feminism. Durham: Duke University Press.

Beecher, Charles. 1853. A review of the "Spiritual Manifestations": Read before the Congregational Association of New York and Brooklyn. New York: Thomas Bosworth.

Bennett, Bridget. 2005. Sacred theatres: Shakers, spiritualists, theatricality, and the Indian in the 1830s and 1840s. TDR/The Drama Review 49 (3): 114-134.

Berry, Catherine. 1876. Experiences in Spiritualism: A record of extraordinary phenomena, witnessed through the most powerful mediums. London: James Burns.

Braude, Ann. 1989. Radical spirits: Spiritualism and women's rights in Nineteenth-Century America. Boston: Beacon Press. 
Britten, Emma Hardinge. 1870. Modern American Spiritualism: A twenty years' record of the communion between Earth and the world of spirits. New York: Published by the author.

Capron, Eliab Wilkinson. 1855. Modern Spiritualism: Its facts and fanaticisms, its consistencies and contradictions. Boston: Bela Marsh.

Cook, James W. 2001. The arts of deception: Playing with fraud in the age of Barnum. Cambridge: Harvard University Press.

Cooper, Robert. 1867. Spiritual experiences: Including seven months with the Brothers Davenport. London: Heywood \& Co.

Daston, Lorraine, and Peter Galison. 2007. Objectivity. New York: Zone Books.

Davenport, Reuben Briggs. 1888. The death blow to Spiritualism: Being the true story of the Fox sisters, as revealed by authority of Margaret Fox and Catherine Fox Jencken. New York: G.W. Dillingham.

Dendy, Walter C. 1832. On the phenomena of dreams, and other transient illusions: Whittaker, Treacher \& Co.

Dobler, Herr. 1869. Exposé of the Davenport Brothers. Belfast: D.\& J. Allen.

Doyle, Arthur Conan. 1926. The history of Spiritualism. London: Cassell.

During, Simon. 2002. Modern enchantments: The cultural power of secular magic. Cambridge, Mass.: Harvard University Press.

Fried, Michael. 1980. Absorption and theatricality: Painting and beholder in the age of Diderot. Berkeley: University of California Press.

Fritz. 1873. Where are the dead? or, Spiritualism explained. Manchester: A. Ireland. Harper, Edith Katherine. 1914. Stead, the man: Personal reminiscences. London: Rider. Herman, Daniel. 2006. Whose knocking? Spiritualism as entertainment and therapy in Nineteenth-Century San Francisco. American Nineteenth Century History 7 (3): 417 - 
442.

Home, Daniel Douglas. 1877. Lights and shadows of Spiritualism. New York: G.W. Carleton \& Co.

Houdini, Harry. 1924. A magician among the spirits. New York: Harper \& Brothers.

James, Tony. 1995. Dream, creativity, and madness in nineteenth-century France. Oxford

New York: Oxford University Press.

King, W. D. 1997. Shadow of a mesmeriser: The female body on the "dark" stage. Theatre Journal 49 (2): 189-206.

Lamont, Peter. 2006. Magician as conjuror: A frame analysis of Victorian mediums. Early Popular Visual Culture 4 (1): 21-33.

Lynch, Eve M. 2004. Spectral politics: The Victorian ghost story and the domestic servant. In The Victorian Supernatural, edited by N. Bown, C. Burdett and P. Thurschwell. Cambridge: Cambridge University Press.

Maskelyne, John Nevil. 1876. Modern Spiritualism: A short account of its rise and progress, with some exposures of so-called spirit media. London: F. Warne.

Mendeleev, Dmitrij Ivanovič. 1992. Sullo spiritismo. Torino: Bollati Boringhieri. Original edition, Materialy dlja suždenija o spiritizme, 1876.

Monroe, John Warne. 2008. Laboratories of faith: Mesmerism, spiritism, and occultism in modern France. Ithaca: Cornell University Press.

Moore, R. Laurence. 1977. In search of white crows: Spiritualism, parapsychology, and American culture. New York: Oxford University Press.

Moore, William D. 1997. To hold communion with nature and the spirit-world: New England's spiritualist camp meetings, 1865-1910. Perspectives in Vernacular Architecture 7: 230-248.

Morse, J. J. 1877. Leaves from my life: A narrative of personal experiences in the career of a 
servant of the spirits. London: James Burns.

Nichols, Thomas Low. 1864. A biography of the Brothers Davenport. London: Saunders, Otley, and Co.

North, Dan. 2008. Performing illusions: cinema, special effects and the virtual actor. London ; New York: Wallflower Press.

Oppenheim, Janet. 1985. The other world: Spiritualism and psychical research in England, 1850-1914. Cambridge: Cambridge University Press.

Owen, Alex. 1990. The darkened room: Women, power and Spiritualism in late Victorian England. Philadelphia: University of Pennsylvania Press.

Oyston, C. G. 1885. Biographical sketch of Mrs. M. A. Hall, Gateshead. The Medium and Daybreak 16 (789): 305-307.

Parssinen, Terry M. 1977. Mesmeric performers. Victorian Studies 21 (1): 87-104.

Peebles, J. M. 1869. Seers of the ages: Embracing Spiritualism, past and present. Boston: William White.

Redman, George A. 1859. Mystic hours: or, Spiritual experiences. New York: C. Partridge.

Rushton, Richard. 2004. Early, classical and modern cinema: Absorption and theatricality. Screen 45 (3): 226-244.

- 2007. Absorption and theatricality in the cinema: Some thoughts on narrative and spectacle. Screen 48 (1): 109-112.

Sexton, George. 1873. Spirit mediums and conjurers: An oration delivered in the Cavendish Rooms, London, on Sunday evening, June 15th, 1873. London: J. Burns.

Taylor, Kelly S. 1996. Exploiting the medium: Anna Cora Mowatt's creation of self through performance. Text and Performance Quarterly 16 (4): 321 - 335.

Wetherbee, John. 1885. Shadows: being a familiar presentation of thoughts and experiences in spiritual matters, with illustrative narrations. Boston: Colby \& Rich. 
Wright, Sarah. 2005. Dropping the mask: Theatricality and absorption in Saenz de Heredia's Don Juan. Screen 46 (4): 415-433. 